\title{
BMJ Open Butyrylcholinesterase as a perioperative complication marker in patients after transcatheter aortic valve implantation: a prospective observational study
}

Bernhard Michels, ${ }^{1}$ Andreas Holzamer, ${ }^{2}$ Bernhard M Graf, ${ }^{3}$ Andre Bredthauer (i) ${ }^{4}$
Walter Petermichl, ${ }^{3}$ Anika Müller, ${ }^{5}$ York Alexander Zausig, ${ }^{6}$ Diane Inge Bitzinger (i) ${ }^{3}$

To cite: Michels $B$,

Holzamer A, Graf BM, et al. Butyrylcholinesterase as a perioperative complication marker in patients after transcatheter aortic valve implantation: a prospective observational study. BMJ Open 2021;11:e042857. doi:10.1136/ bmjopen-2020-042857

- Prepublication history for this paper is available online. To view these files, please visit the journal online (http://dx.doi. org/10.1136/bmjopen-2020042857).

Received 30 July 2020 Accepted 05 May 2021

Check for updates

(C) Author(s) (or their employer(s)) 2021. Re-use permitted under CC BY-NC. No commercial re-use. See rights and permissions. Published by BMJ.

For numbered affiliations see end of article.

Correspondence to Dr Diane Inge Bitzinger; diane.bitzinger@ukr.de

\section{ABSTRACT}

Objectives Transcatheter aortic valve implantation (TAVI) is performed in elderly patients with severe aortic valve stenosis and increased operative risks. We tested the hypothesis that acetylcholinesterase (AChE) and butyrylcholinesterase (BChE) have a predictive value for prevalent complications after TAVI and could serve as indicators of systemic inflammation in the early postoperative period.

Design Prospective observational study.

Setting This study is a secondary analysis of multicentre CESARO- study.

Participants 48 patients with TAVI were included and 43 obtained the complete assessment.

Primary and secondary outcome measures Patients' clinical parameters, demographic data, peripheral AChE and $\mathrm{BChE}$ activities and routine blood markers were assessed throughout the perioperative period using bedside point-of-care measurements for $\mathrm{AChE}$ and $\mathrm{BChE}$. Postoperative complication screening was conducted up to the third postoperative day and included infections, delirium and heart-rhythm disturbances. After assessment, the patients were divided into complication and noncomplication group.

Results Of 43 patients, 24 developed postsurgical complications (55.8\%). Preoperative assessment showed no significant differences regarding demographic data and laboratory markers, but preoperative BChE levels were significantly lower in patients who developed postoperative complications (complication group $2589.2 \pm 556.4$ vs noncomplication group $3295.7 \pm 628.0$, Cohen's $r=0.514$, $\mathrm{p}<0.001)$. In complication group, we observed an early, sustained reduction in $\mathrm{BChE}$ activity from preoperative to postoperative period. In complication group, BChE levels were significantly lower at each time point compared with noncomplication group. AChE activity showed no significant difference between both groups. Complication group also had longer stay in hospital overall.

Conclusion BChE could be a useful perioperative biomarker to identify patients with a higher risk for postoperative complications after TAVI. By using point-ofcare measurements, the levels of BChE are fast available and can lead to an early targeted therapy. Predicting the length of the hospital stay might play an important role in staff and resource management for these patients. Trial registration number NCT01964274; Post-results.
Strengths and limitations of this study

- This study is a secondary analysis of the prospective observational multicentre CESARO study.

- Our study included 48 cardiosurgical patients with an observation time of 3 days.

- Butyrylcholinesterase could be a useful perioperative biomarker to identify patients with a higher risk for postoperative complications after transcatheter aortic valve implantation.

- By using point-of-care measurements, the levels of $\mathrm{BChE}$ are fast available and can lead to an early targeted therapy.

- Predicting the length of the hospital stay might play an important role in staff and resource management for these patients.

\section{INTRODUCTION}

Recently, transcatheter aortic valve implantation (TAVI) has become the therapeutic standard for medical treatment in elderly, multimorbid patients with severe aortic valve stenosis and increased operative risks. ${ }^{12}$ TAVI involves the implantation of a prosthetic valve, which is introduced with a catheter through transfemoral (TF), transapical (TA) or direct transaortic access. Usually, the TF approach is preferred because thoracotomy and penetration of the myocardium are not needed. The TA approach is common, if severe atherosclerotic disease does not allow retrograde insertion of the catheter. In patients with severe aortic stenosis, who could not undergo a surgical replacement of the aortic valve, TAVI significantly reduced the rates of death at any cause, compared with standard therapy. ${ }^{3}$ However, previous studies have shown that pneumonia, acute renal failure, indication for a permanent pacemaker and delirium were the most frequently recorded complications after TAVI. ${ }^{4}$ Covello et a $\overline{\tilde{p}}$ reported a pneumonia rate of $7 \%-8 \%$ after TAVI. The 
incidence of delirium after TAVI is reported as $29 \%$ in the literature. ${ }^{6}$

Acetylcholinesterase (AChE) and butyrylcholinesterase (BChE) are the focus of current research. Recent studies have shown that AChE and BChE serve as diagnostic markers of low-grade systemic inflammation. ${ }^{7-9}$ Rapid changes in cholinesterase activity have also been reported in patients after acute trauma, infections, burns and critical illness. ${ }^{10-14}$ Both enzymes may serve as indicators of systemic inflammation and may have a predictive value for mortality in critically ill patients. Zivkovic et $a l^{13}$ showed that reduced serum activity of BChE indicates severe systemic inflammation in critically ill patients. Furthermore, a recent study showed that a sustained reduction in serum cholinesterase enzyme activity predicts patient outcome following sepsis. ${ }^{15}$

Other studies postulate low preoperative plasma cholinesterase activity as a risk marker of postoperative delirium in elderly patients. ${ }^{16} \mathrm{~A}$ recently published study on cholinesterase activity in cardiac surgical patients showed no postoperative differences in cholinesterase activities between delirious and nondelirious patients but showed a perioperative decrease in $\mathrm{BChE}$, which was potentially caused by cardiopulmonary bypass. ${ }^{17}$ However, due to high variability in the aetiology and progress of clinical conditions, it was difficult to determine whether the changes in the enzyme activity correlated with the emergence of disease or were affected by concomitant factors such as cardiopulmonary bypass.

This is the first study to investigate the roles of AChE and BChE as inflammatory markers in cardiac surgical patients under standardised perioperative conditions without using cardiopulmonary bypass. Our aim of the present study is to evaluate if there is a predictive association of perioperative determination of $\mathrm{AChE}$ and $\mathrm{BChE}$ activity and the occurrence of postoperative complications after TAVI.

\section{MATERIALS AND METHODS}

\section{Ethics approval statement and patient population}

This work is a secondary analysis of the prospective observational multicentre CESARO study, powered for the detection of postoperative delirium. The CESARO study was initiated at Charité-Universitätsmedizin Berlin, Department of Anesthesiology and Operative Intensive Care Medicine.

Inclusions criteria: minimum age of 18 years, admission to intensive care unit (ICU) following elective TAVI in general anaesthesia.

Exclusion criteria: missing consent, patients with a known pseudocholinesterase deficiency, patients with language, visual or hearing impairments.

\section{Data}

Data were acquired from anaesthetic charts (Medlinq V.1.3, Hamburg, Germany), the patient document system used in the ICU (Metavision, iMDsoft, Tel Aviv, Israel) and medical reports from the electronic hospital information system (SAP, Walldorf, Germany) from the preoperative, intraoperative and postoperative periods until the patients were discharged from the hospital.

\section{Preoperative variables}

Preoperative data included demographic data, such as age, sex, height, weight, regular use of alcohol and nicotine, American Society of Anesthesiologists (ASA) class, logistic European System for Cardiac Operative Risk Evaluation (EuroSCORE), New York Heart Association class and left ventricular ejection fraction. The patients' previous medical history was examined for conditions such as chronic kidney disease, cerebrovascular events, including stroke and transient ischaemic attacks, myocardial infarction, chronic obstructive pulmonary disease, diabetes mellitus and pre-existing cardiac arrhythmias. Furthermore, we evaluated the preoperative anticholinergic burden using the anticholinergic drug scale. ${ }^{18}$ This scale ranges from 0 (no anticholinergic activity) to 3 (highest anticholinergic activity). Each long-term drug was screened for its anticholinergic activity, and for each patient, the number of points was assessed. Every patient was screened for preoperative delirium, using the nursing delirium screening scale (NU-DESC). Preoperative assessment of AChE, BChE, C reactive protein (CRP), leucocytes, haemoglobin and creatinine was performed (table 1).

\section{Intraoperative variables}

Key elements of intraoperative data included the selected access type, anaesthetic procedure, transfusion of erythrocyte concentrates and extubation rate as well as the procedure duration.

\section{Postoperative variables}

Postoperative data included the patient's stay in the ICU and the stay in hospital in general. Next to the sampling of laboratory markers, every patient was screened for delirium with NU-DESC for the first 3 days after surgery. Patients were daily assessed for pain, using the numeric rating scale (NRS score: $0=$ no pain $-10=$ maximum pain). Furthermore, any complication in recovery time was noticed. Mortality reasons are divided into cardiac, acute kidney injury, cardiovascular events and infections.

\section{Variables}

\section{Delirium}

Delirium screening was conducted perioperatively using a validated screening tool (NU-DESC) ${ }^{19}$ NU-DESC assesses five dimensions: orientation, behaviour, communication, illusion/hallucination and psychomotor retardation. The symptoms are rated on a three-point scale, whereas a score of 2 or more cumulative points indicated delirium. Delirium assessment was performed 1 day prior to the operation, on admission to ICU and daily up to the third postoperative day. Patients with Richmond Agitation Sedation Scale $\leq-2$ were excluded for the current testing. 
Table 1 Description of baseline data; all data are presented as $n$ (number) and (\%)

\begin{tabular}{|c|c|}
\hline Characteristic & Total sample $(n=43)$ \\
\hline Age (years) (M (SD)) & $79.47(5.7)$ \\
\hline \multicolumn{2}{|l|}{$\operatorname{Sex}(n(\%))$} \\
\hline Male & $22(51.2)$ \\
\hline Female & $21(48.8)$ \\
\hline BMI (M (SD)) & $27.93(5.4)$ \\
\hline \multicolumn{2}{|l|}{ ASA-PS (n (\%)) } \\
\hline 3 & $32(74.4)$ \\
\hline 4 & $11(25.6)$ \\
\hline \multicolumn{2}{|l|}{ Operative procedure (n (\%)) } \\
\hline Transapicale TAVI & $11(25.6)$ \\
\hline Transfemorale TAVI & $32(74.4)$ \\
\hline \multicolumn{2}{|l|}{ Relevant comorbidities (n (\%)) } \\
\hline Hypertension & $37(86)$ \\
\hline Diabetes & $16(37.2)$ \\
\hline Congestive heart failure & $36(83.7)$ \\
\hline Congestive kidney failure & $20(46.5)$ \\
\hline Coronary heart disease & $31(72.1)$ \\
\hline Cardiac arrhythmias & $25(58.1)$ \\
\hline Stroke & $8(18.6)$ \\
\hline Nicotine & 19 (44.2) \\
\hline Alcohol & $8(18.6)$ \\
\hline Hypothyreosis & $10(23.3)$ \\
\hline Hypercholesterinemia & $14(32.6)$ \\
\hline \multicolumn{2}{|l|}{ EuroSCORE (n (\%)) } \\
\hline Low & $15(34.9)$ \\
\hline Middle & $18(41.9)$ \\
\hline High & $10(23.3)$ \\
\hline Pre-operative anticholinergic drugs & $16(37.2)$ \\
\hline
\end{tabular}

ASA, American Society of Anaesthesiologists Classification; BMI, body mass index; TAVI, transcatheter aortic valve implantation.

\section{Laboratory parameters}

Blood samples were taken from every patient at following time points: 1 day before operation (screening), shortly before anaesthetic induction, on admission to ICU, 1 day after surgery and 2 days after surgery (figure 1). The measurements included the determination of AChE and
BChE. Both were measured in $10 \mu \mathrm{l}$ whole blood, using ChE check mobile, a validated point-of-care testing device (ChE check mobile, Securetec Detektions-Systeme AG, Neubiberg, Germany; In-Vitro-Diagnostics Guideline 98/79/EG; DIN EN ISO 18113-2 and -3) by following the manufacturer's instructions. Also, blood count, CRP, creatinine were measured at each time point. Creatine kinase (CK) and heart enzymes (CK-MB) were measured on the first postoperative day in the normal laboratory control. Brain natriuretic Peptide (NT-proBNP) was measured at the screening day. To deal with missing values, we included three defined measurements (time points) into the analysis.

\section{Postoperative complications}

Since delirium, pneumonia, heart rhythm disturbances and acute renal failure are the most frequently reported complications after TAVI, ${ }^{4}$ we have screened all patients until the discharge of the hospital. Infection was defined as an increase in CRP, fever and diagnosed infection-focus (pneumonia, urinary tract infection, other infections). Delirium was diagnosed by using NU-DESC. Postoperative heart rhythm disturbances were occurred by AV block and atrial fibrillation. Patients were divided into two groups: those who did not develop any postoperative complications (noncomplication group) and patients who showed one of these complications within 3 days after TAVI (complication group).

\section{Operation procedure}

All patients were admitted and evaluated at least 1 day before the operation. TAVIs were performed by the cardiac team (cardiac surgeon, cardiologist and cardiac anaesthetist) in a hybrid operating theatre, according to the German guidelines for TAVI procedures. All procedures were performed with the patients placed under general anaesthesia. In all patients, monitoring consisted of pulsoximetry, five-channel ECG, invasive blood pressure, central venous pressure, urinary output and bladder temperature. The maintenance of normothermia was accomplished by a heating blanket placed beneath the patient. The patients received right ventricular pacemakers for rapid ventricular pacing during balloon aortic valvuloplasty and valve expansion. Preoxygenation was performed with pure oxygen using a facemask. Anaesthesia was induced with etomidate (Etomidat-Lipuro, B. Braun Melsungen AG, Melsungen,

\begin{tabular}{|c|c|c|c|c|}
\hline D O (Screening) & $\begin{array}{c}\text { D } 1 \\
\text { (anestehsia } \\
\text { induction) }\end{array}$ & $\begin{array}{c}\text { POD } 0 \\
\text { admission to } \\
\text { ICU) }\end{array}$ & $\begin{array}{l}\text { POD } 1 \text { (first } \\
\text { postoperative } \\
\text { day) }\end{array}$ & $\begin{array}{c}\text { POD } 2 \text { (second } \\
\text { postoperative } \\
\text { day) }\end{array}$ \\
\hline
\end{tabular}

Figure 1 Timeline of measurements of $\mathrm{BChE}$ and AChE: blood samples were taken 1 day preoperative (D O), shortly before anaesthetic induction (D 1), on admission to ICU (POD 0), 1 day after surgery (POD 1) and 2 days after surgery (POD 2). If the measuremnets could not be conducted immediatley, the samples have been cooled in a refrigerator and the measurement was performed up to 2 hours later. AChE, acetylcholinesterase; BChE, butyrylcholinesterase; ICU, intensive care unit, POD, Postoperative Day. 
Germany), remifentanil (Ultiva, GlaxoSmithKline GmbH KG, Munich, Germany) and rocuronium (Rocuronium Inresa, Inresa Arzneimittel GmbH, Freiburg, Germany) and maintained with sevoflurane (Sevorane, AbbVie Deutschland GmbH KG, Wiesbaden, Germany). Piritramide and metamizole were used as additional pain medication. PONV (postoperative nausea and vomiting) prophylaxis was used intraoperatively, depending on the patient's risk. Cardiovascular drugs (eg, norepinephrine and dobutamine) were administered, as needed. A prophylactic antibiotics (1.5 g, Cefuroxim Hikma, Hikma Pharma GmbH, Gräfelfing, Germany) was administered to each patient. In the operating theatre, the patient was connected to a defibrillator, and a TEE (transesophageal echocardiography) probe was introduced. After preparing the access points and anticoagulation with heparin (Ratiopharm GmbH, Ulm, Germany; mean given dose $5293 \pm 2643 \mathrm{IU})$, the native valve was opened under rapid ventricular pacing, and the prothesis was implanted. The position and function of the prothesis were verified with TEE. Extubation of the patient was the goal at the end of each procedure. After surgery, patients were monitored for at least 12 hours in the ICU. Following this period, patient care continued either in the ICU or in the general ward. There was no use of heart-lung machines.

\section{Patient and public involvement}

Patients were not involved in the study.

\section{Statistics}

The data were electronically gathered and stored by using Excel (Excel 2013, Microsoft Corporation, Redmond, Washington). Data analysis was performed by using SPSS (V22.0; SPSS, Chicago, Illinois). Frequency distributions and percentage rates were used for the categorical variables. Data are presented as mean with SD and with Cohen's r effect size. Shapiro-Wilk test was used to verify Gaussian distribution of the study groups. Statistical significance between the patient groups was tested using t-test, Mann-Whitney U test, analysis of variance and chiquadrat. Bonferroni correction was done in case of repeat measurements to rule out alpha error accumulation. Friedman analysis of ranks was performed to compare the cholinesterase activity change over time in each group. A multivariate logistic regression analysis was performed to investigate the association between cholinesterase activity and postoperative complications. A $\mathrm{p}$ value $<0.05$ indicated statistical significance.

\section{RESULTS}

\section{Baseline data}

A total of 48 patients were included, and 43 patients completed the assessment battery. The mean age was $79.5 \pm 5.71$ years and the mean body mass index was $27.93 \pm 5.36$. There were almost equally men and women (22 $(51.2 \%)$ vs $21(48.8 \%)$, table 1$)$. All patients received elective TAVI in general anaesthesia. TF access was selected for $32(74 \%)$, with TA chosen for $11(26 \%)$ patients. There was no use of heart-lung machines. The demographic data and pre-existing conditions are shown in table 1. Thirty-two $(74.4 \%)$ had an ASA-class of three, $11(25.6 \%)$ of four. Except of four, every patient was extubated immediately after operation and brought to ICU. One high-risk patient was still intubated when brought to ICU and died 2 days after operation by multiorgan failure. Another patient was extubated on the first postoperative day. Two patients were extubated a few hours after brought to ICU. Patients were discharged to a normal ward after 1 day and left the hospital after 13.28 \pm 6.2 days.

\section{Postoperative complications}

Twenty-four patients (55.8 \%) had postoperative complications as defined above. One multimorbid and high-risk patient died due to multiorgan failure at ICU 2 days after surgery.

Of 43 patients, 12 developed postoperative delirium $(27.9 \%)$. Most patients developed their delirium on the first day after surgery.

Of 43 patients, 2 developed pneumonia. However, in three patients with raised infection markers and suspected infection, no focus was found. All of them received antibiotics.

There were seven patients with postoperative indication for pacemaker (16.3\%). Overall, 12 patients developed heart rhythm disturbances $(27.9 \%)$. Some of the patients developed more than one complication, for example, delirium or infection.

\section{Comparison between complication and noncomplication group \\ Preoperative variables}

Preoperative assessment showed no statistically significant differences regarding demographic data and laboratory routine markers like haemoglobin $(\mathrm{p}=0.917)$, leucocytes $\quad(p=0.383), \quad$ CRP $\quad(p=0.716), \quad$ NT-proBNP $(\mathrm{p}=0.563)$ and creatinine $(\mathrm{p}=0.089)$. Preoperative $\mathrm{BChE}$ levels were significantly lower in patients who developed postoperative complications (D 1 complication group $2589.2 \pm 556.4$ vs D 1 noncomplication group $3295.7 \pm 628.0$ Cohen's $\mathrm{r}=0.514, \mathrm{p}<0.001$, table 2). Preoperative AChE enzyme activity in contrast did not show any statistically significant difference between complication and noncomplication groups. There was no statistically significant difference regarding pre-existing anticholinergic medication $(p=0.153)$. There was also no statistically significant difference regarding alcohol $(\mathrm{p}=0.226)$ or nicotine $(\mathrm{p}=0.807)$ consumption. Men or women did not show a significantly higher incidence of postoperative complications $(p=0.095)$. There was no statistically significant difference between complication and noncomplication group regarding the anticholinergic burden $(\mathrm{p}=0.229)$.

\section{Postoperative variables}

All patients were postoperatively admitted to the ICU extubated and haemodynamic supported by catecholamines. 
Table 2 Perioperative laboratory markers; all data are presented as number $(n)$ or as mean \pm SD

\begin{tabular}{|c|c|c|c|c|c|c|}
\hline Variables & Complication & $\mathbf{N}$ & $\mathbf{M}$ & SD & $P$ value & Cohens' r \\
\hline \multirow[t]{2}{*}{ EuroSCORE } & Yes & 24 & 21.8 & 15.4 & 0.824 & 0.034 \\
\hline & no & 19 & 22.8 & 13.5 & & \\
\hline \multirow{2}{*}{$\begin{array}{l}\text { Weight } \\
(\mathrm{kg})\end{array}$} & Yes & 24 & 78.3 & 15.5 & 0.504 & 0.102 \\
\hline & no & 19 & 74.9 & 18.0 & & \\
\hline \multirow{2}{*}{$\begin{array}{l}\mathrm{BMI} \\
\left(\mathrm{kg} / \mathrm{m}^{2}\right)\end{array}$} & Yes & 24 & 28.1 & 4.7 & 0.860 & 0.037 \\
\hline & No & 19 & 27.7 & 6.2 & & \\
\hline \multirow{2}{*}{$\begin{array}{l}\text { Age } \\
\text { (years) }\end{array}$} & Yes & 24 & 79.9 & 5.3 & 0.556 & 0.086 \\
\hline & No & 19 & 78.9 & 6.3 & & \\
\hline \multirow[t]{2}{*}{ NT-proBNP(pg/ml) } & Yes & 24 & 6244.8 & 6773.1 & 0.563 & 0.099 \\
\hline & No & 19 & 4806.6 & 7809.4 & & \\
\hline \multirow[t]{2}{*}{ Haemoglobin D O(g/L) } & Yes & 24 & 12.1 & 1.9 & 0.917 & 0.029 \\
\hline & no & 19 & 12.2 & 1.4 & & \\
\hline \multirow[t]{2}{*}{ Haemoglobin POD O(g/L) } & Yes & 24 & 10.7 & 1.5 & 0.565 & 0.068 \\
\hline & No & 19 & 10.9 & 1.4 & & \\
\hline \multirow[t]{2}{*}{ Haemoglobin POD $1(\mathrm{~g} / \mathrm{L})$} & Yes & 24 & 10.1 & 1.4 & 0.986 & 0.000 \\
\hline & no & 19 & 10.1 & 1.1 & & \\
\hline \multirow[t]{2}{*}{ Haemoglobin POD 2(g/L) } & Yes & 24 & 10.1 & 1.1 & 0.673 & 0.087 \\
\hline & No & 19 & 10.3 & 1.2 & & \\
\hline \multirow[t]{2}{*}{ Haemoglobin POD 3(g/L) } & Yes & 24 & 9.6 & 1.0 & 0.272 & 0.173 \\
\hline & No & 19 & 10.0 & 1.3 & & \\
\hline \multirow[t]{2}{*}{ Creatinine D O(mg/dl) } & Yes & 24 & 1.4 & 0.7 & 0.089 & 0.247 \\
\hline & No & 19 & 1.1 & 0.4 & & \\
\hline \multirow[t]{2}{*}{ Creatinine POD $1(\mathrm{mg} / \mathrm{dl})$} & Yes & 24 & 1.2 & 0.4 & 0.347 & 0.124 \\
\hline & No & 19 & 1.1 & 0.4 & & \\
\hline \multirow[t]{2}{*}{ Creatinine POD 2(mg/dl) } & Yes & 24 & 1.5 & 0.8 & 0.188 & 0.223 \\
\hline & No & 19 & 1.2 & 0.4 & & \\
\hline \multirow[t]{2}{*}{ Creatinine POD 3(mg/dl) } & Yes & 24 & 1.5 & 1.0 & 0.240 & 0.244 \\
\hline & No & 19 & 1.1 & 0.4 & & \\
\hline \multirow{2}{*}{$\begin{array}{l}\text { Leucocytes } \\
\text { D } 0(/ \mathrm{nl})\end{array}$} & Yes & 24 & 7.8 & 2.1 & 0.383 & 0.131 \\
\hline & No & 19 & 7.3 & 1.6 & & \\
\hline \multirow{2}{*}{$\begin{array}{l}\text { Leucocytes } \\
\text { POD } 1(/ n l)\end{array}$} & Yes & 24 & 9.6 & 4.3 & 0.496 & 0.113 \\
\hline & No & 19 & 8.8 & 2.1 & & \\
\hline \multirow[t]{2}{*}{ Leucocytes POD 2(/nl) } & Yes & 24 & 9.9 & 2.7 & 0.616 & 0.081 \\
\hline & No & 19 & 9.4 & 3.5 & & \\
\hline \multirow[t]{2}{*}{ Leucocytes POD 3(/nl) } & Yes & 24 & 8.8 & 3.1 & 0.079 & 0.336 \\
\hline & No & 19 & 7.0 & 1.5 & & \\
\hline \multirow{2}{*}{$\begin{array}{l}\text { CRP } \\
\text { D 0(mg/l) }\end{array}$} & Yes & 24 & 16.3 & 17.8 & 0.716 & 0.094 \\
\hline & No & 19 & 19.8 & 18.2 & & \\
\hline \multirow{2}{*}{$\begin{array}{l}\text { CRP } \\
\text { POD 1(mg/l) }\end{array}$} & Yes & 24 & 31.8 & 21.1 & 0.177 & 0.236 \\
\hline & No & 19 & 22.0 & 18.9 & & \\
\hline \multirow{2}{*}{$\begin{array}{l}\text { CRP } \\
\text { POD 2(mg/l) }\end{array}$} & Yes & 24 & 116.3 & 52.9 & 0.516 & 0.114 \\
\hline & No & 19 & 101.3 & 78.2 & & \\
\hline \multirow{2}{*}{$\begin{array}{l}\text { CRP } \\
\text { POD 3(mg/l) }\end{array}$} & Yes & 24 & 115.3 & 68.5 & 0.113 & 0.284 \\
\hline & No & 19 & 72.7 & 76.0 & & \\
\hline
\end{tabular}




\begin{tabular}{|c|c|c|c|c|c|c|}
\hline Variables & Complication & $\mathbf{N}$ & $M$ & SD & $P$ value & Cohens' $r$ \\
\hline \multirow{2}{*}{$\begin{array}{l}\mathrm{BChE} \\
\mathrm{D} 0(\mathrm{U} / \mathrm{I})\end{array}$} & Yes & 24 & 2784.0 & 534.9 & 0.118 & 0.238 \\
\hline & No & 19 & 3072.6 & 652.1 & & \\
\hline \multirow{2}{*}{$\begin{array}{l}\mathrm{BChE} \\
\mathrm{D} 1(\mathrm{U} / \mathrm{l})\end{array}$} & Yes & 24 & 2589.2 & 556.4 & $<0.001$ & 0.514 \\
\hline & No & 19 & 3295.7 & 628.0 & & \\
\hline \multirow{2}{*}{$\begin{array}{l}\text { BChE } \\
\text { POD 0(U/I) }\end{array}$} & Yes & 24 & 2379.6 & 525.1 & $<0.001$ & 0.469 \\
\hline & No & 19 & 2972.5 & 599.2 & & \\
\hline \multirow{2}{*}{$\begin{array}{l}\text { BChE } \\
\text { POD 1(U/I) }\end{array}$} & Ye & 24 & 2300.3 & 561.0 & $<0.001$ & 0.504 \\
\hline & No & 19 & 2936.1 & 523.1 & & \\
\hline \multirow{2}{*}{$\begin{array}{l}\text { BChE } \\
\text { POD 2(U/I) }\end{array}$} & Yes & 24 & 2166.7 & 537.0 & 0.002 & 0.462 \\
\hline & No & 19 & 2713.5 & 510.6 & & \\
\hline \multirow{2}{*}{$\begin{array}{l}\text { AChE } \\
\text { D O(U/gHb) }\end{array}$} & Yes & 24 & 45.0 & 8.1 & 0.446 & 0.118 \\
\hline & No & 19 & 43.3 & 6.0 & & \\
\hline \multirow{2}{*}{$\begin{array}{l}\text { AChE } \\
\text { D 1(U/gHb) }\end{array}$} & Yes & 24 & 42.0 & 10.0 & 0.263 & 0.172 \\
\hline & No & 19 & 39.2 & 4.7 & & \\
\hline \multirow{2}{*}{$\begin{array}{l}\text { AChE } \\
\text { POD } 0(\mathrm{U} / \mathrm{gHb})\end{array}$} & Yes & 24 & 42.9 & 10.0 & 0.051 & 0.295 \\
\hline & No & 19 & 37.6 & 6.4 & & \\
\hline \multirow{2}{*}{$\begin{array}{l}\text { AChE } \\
\text { POD } 1(\mathrm{U} / \mathrm{gHb})\end{array}$} & Yes & 24 & 41.5 & 9.2 & 0.196 & 0.198 \\
\hline & No & 19 & 38.4 & 5.2 & & \\
\hline \multirow{2}{*}{$\begin{array}{l}\text { AChE } \\
\text { POD 2(U/gHb) }\end{array}$} & Yes & 24 & 41.2 & 8.2 & 0.058 & 0.294 \\
\hline & No & 19 & 36.5 & 6.8 & & \\
\hline \multirow{2}{*}{$\begin{array}{l}\text { CK } \\
\text { POD 1(U/I) }\end{array}$} & Yes & 24 & 189.6 & 186.8 & 0.953 & 0.009 \\
\hline & No & 19 & 186.1 & 190.5 & & \\
\hline \multirow{2}{*}{$\begin{array}{l}\text { CK-MB } \\
\text { POD } 1(\mathrm{ng} / \mathrm{ml})\end{array}$} & Yes & 24 & 15.5 & 18.2 & 0.946 & 0.012 \\
\hline & No & 19 & 15.9 & 14.3 & & \\
\hline \multirow{2}{*}{$\begin{array}{l}\text { CK Index } \\
\text { POD } 1\end{array}$} & Yes & 24 & 7.2 & 3.6 & 0.314 & 0.174 \\
\hline & No & 19 & 8.5 & 3.8 & & \\
\hline \multirow{2}{*}{ Stay in hospital (days) } & Yes & 24 & 15.2 & 6.3 & 0.033 & 0.325 \\
\hline & No & 19 & 11.1 & 5.5 & & \\
\hline \multirow[t]{2}{*}{ Anticholinergic burden } & Yes & 24 & 0.82 & 1.191 & 0.229 & 0.189 \\
\hline & No & 19 & 0.42 & 0.838 & & \\
\hline
\end{tabular}

AChE, acetylcholinesterase; BChE, butyrylcholinesterase; BMI, body mass index; CK, creatine kinase; CRP, C reactive protein; MB, MuscleBrain type; NT-proBNP, brain natriuretic peptide; POD, postoperative day.

Two patients did not meet the extubation criteria in the operation room and were extubated a few hours later at ICU. One high-risk patient died at ICU due to multiorgan failure. One patient was extubated on the first postoperative day.

Complication group showed an early, sustained and statistically significant decrease in BChE activity from the preoperative to the first postoperative measurement (D 0: $2784.0 \pm 534.9$ vs POD 0: 2379.6 $\pm 525.1, \mathrm{p}<0.001$, figure 2 ). In contrast in patients without postoperative complications, we observed a delayed decrease in BChE activity from the preoperative to postoperative period (D 0: $3072.6 \pm 652.1$ vs POD 2: $2713.5 \pm 510.6, \mathrm{p}<0.001$, figure 2). In all time points, a significantly lower BChE activity was observed in patients with complications compared with patients without postoperative complication (figure 2).

Further analysis involving partial correlation and regression analysis showed that there was no influence of preoperative anticholinergic medication on BChE results ( $\mathrm{p}=\mathrm{ns})$.

Both groups showed a moderate decrease in AChE activity after preoperative screening measurement (figure 3). From anaesthesia induction to the second postoperative measurement, we observed no significant changes in AChE activity over time in both groups. There were no significant differences in AChE activity between patients with and without complication in any time point (figure 3). 


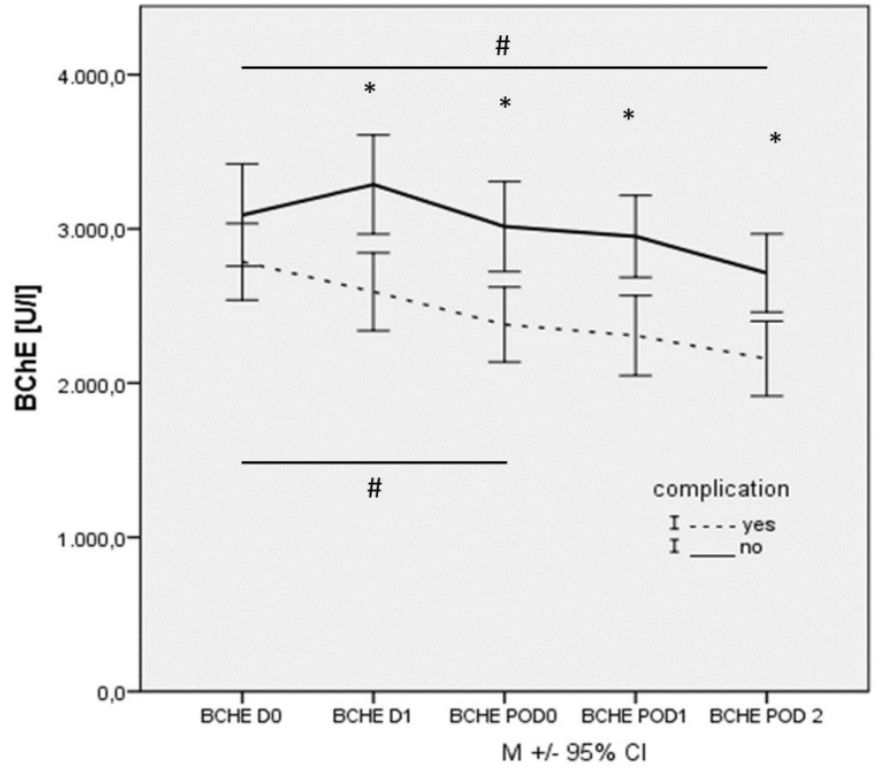

Figure 2 Time trajectories of BChE activities in patients with TAVI $(n=43)$. Pre-operative (DO), shortly before anaesthetic induction (D 1), on admission to ICU (POD 0), 1 day after surgery (POD 1) and 2 days after surgery (POD 2) measurements in patients with (dashed) and without (solid) complication. Data are presented as median \pm SD. *Difference between groups; " Difference within groups. BChE, butyrylcholinesterase; TAVI, transcatheter aortic valve implantation.

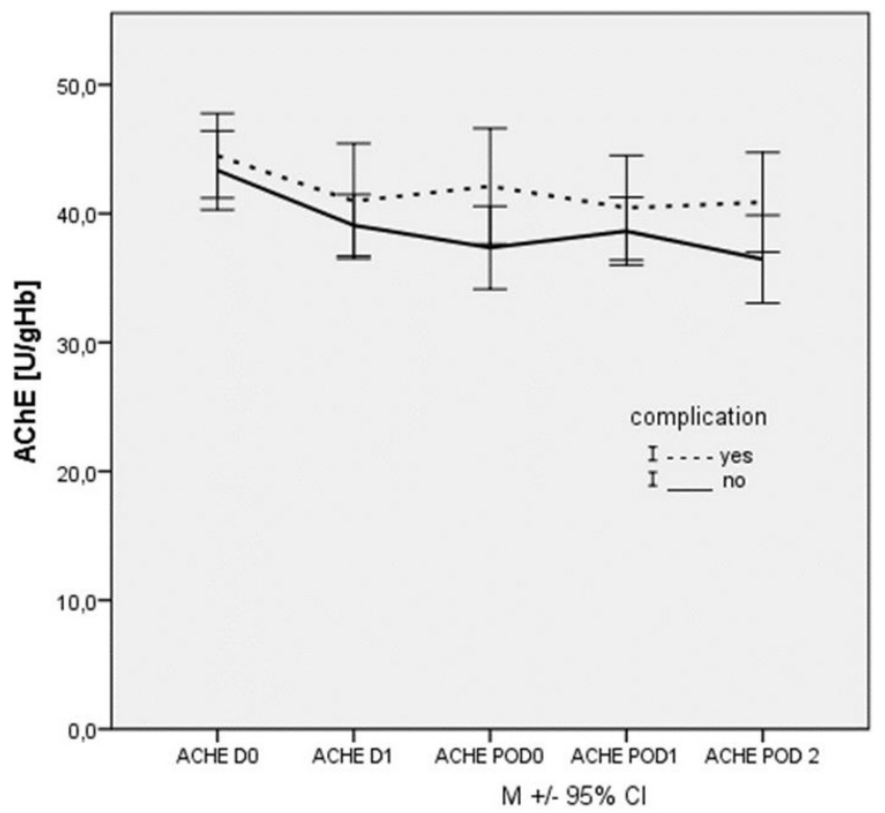

Figure 3 Time trajectories of AChE activities in patients with TAVI $(n=43)$. Pre-operative (DO), shortly before anaesthetic induction (D 1), on admission to ICU (POD 0), 1 day after surgery (POD 1) and 2 days after surgery (POD 2) measurements in patients with (dashed) and without (solid) complication. Data are presented as median \pm SD. AChE, acetylcholinesterase; TAVI, transcatheter aortic valve implantation.
Further analysis showed large effect sizes for the perioperative measurements of $\mathrm{BChE}$. In contrast, effect sizes for AChE were much lower, which affirms the results above (table 2).

Patients, who developed postoperative complications, had a significantly longer stay in hospital in general (complication group: $15.2 \pm 6.3$ vs noncomplication group: $11.1 \pm 5.5$ days, Cohen's $\mathrm{r}=0.325, \mathrm{p}=0.033$ ). There was no statistically significant difference regarding the stay on ICU (complication group vs noncomplication group Cohen's $\mathrm{r}=0.132, \mathrm{p}=0.379$ ). Patients with postoperative delirium showed highest NU-DESC score on the first postoperative day (delirium: 3.3 \pm 2.6 vs nondelirium: $0.27 \pm 0.79)$. The preoperative score of NU-DESC was $0.42 \pm 0.67$ within patients who developed postoperative delirium. Routine laboratory markers like haemoglobin, leucocytes, CRP, CK, CK-MB and creatinine did not show any statistically significant difference (complication group vs noncomplication group $\mathrm{p}=\mathrm{ns}$, table 2 ).

Furthermore, there was no statistically significant difference in EuroSCORE regarding on complication (complication group vs noncomplication group Cohen's $r=0.034$, $\mathrm{p}=0.824$, table 1 ).

\section{TA versus TF}

Patients who underwent TA approach declared postoperative higher pain levels measured by NRS $(\mathrm{p}<0.001)$. They also showed higher CRP levels on POD 2 (88.8 \pm 44.5 vs $161.6 \pm 70.2$, Cohen's $\mathrm{r}=0.574, \mathrm{p}<0.001)$ and higher levels of CK $(110.8 \pm 134.5$ vs $398.7 \pm 139.0$, Cohen's $\mathrm{r}=0.728, \mathrm{p}<0.001)$ and CK-MB $(8.3 \pm 11.8$ vs $29.8 \pm 14.7$, Cohen's $r=0.650, p<0.001$ ) on the first postoperative day. There were no further statistically significant differences between patients with TF and TA approach, especially regarding on complications or BChE and AChE enzyme levels.

\section{DISCUSSION}

TAVI has become the therapeutic standard for medical treatment in elderly patients with severe aortic valve stenosis and increased operative risks. The primary objective of the present investigation was to evaluate the roles of AChE and BChE as predictive markers for prevalent complications in cardiosurgical patients after TAVI.

Previous studies assumed an interaction of the immune and cholinergic system ${ }^{20}$ and identified AChE and BChE as useful biomarkers for early detection of patients with emerging inflammation. ${ }^{16}$ Rapid changes in cholinesterase activity have been reported in patients after acute trauma, infections, delirium and critical illness. ${ }^{10-14}$ Both enzymes may serve as indicators of systemic inflammation and may have a predictive value for mortality in critically ill patients. Zivkovic et $a l^{10}$ showed that bedsidemeasurement of BChE activity predicts patient morbidity and length of ICU stay following major traumatic injury. ${ }^{21}$ Another study with patients undergoing venoarterial extracorporeal membrane oxygenation therapy after 
cardiac surgery revealed BChE as a strong predictor of all-cause and cardiovascular mortality.

In our present study, patients with postoperative complications after TAVI had significant lower preoperative levels of BChE compared with the noncomplication group. Effect sizes were particularly large for BChE measurements in this homogeneous patient group. In combination with common preoperative evaluation procedures, BChE activity may serve as a useful predictive indicator to identify high-risk patients. Future studies are needed to clarify clinical implications.

Due to high variability in the onset, aetiology and progress of clinical conditions among patients, determining whether changes in the enzyme activity are correlated with the emergence of disease or are affected by concomitant factors is difficult. John $e t a l^{17}$ tested the hypothesis that AChE and BChE have an impact on patients after cardiac surgery with postoperative delirium. They showed that AChE increased and BChE decreased within the first 3 days after surgery but did not discern between patients with and without delirium. The authors supposed that the perioperative change of $\mathrm{AChE}$ and $\mathrm{BChE}$ activity might possibly be explained by an interaction of AChE and $\mathrm{BChE}$ and the use of a cardiopulmonary bypass. In our present study, we evaluated the role of AChE and BChE activity in cardiosurgical patients after TAVI, as a standardised operative procedure without cardiopulmonary bypass. We could show that complication group showed a significantly perioperative decrease in BChE within the first 3 days after TAVI, despite the fact that there was no use of heart-lung machines in our patients. Furthermore, there was no use of blood products in the present study, so we can rule out a possible interaction of AChE and BChE with blood products as well. While in the CESARO study, a wide spectrum of operative disciplines has been analysed, and the perioperative enzyme activities showed small effect sizes, we can show large effect sizes for BChE in this secondary analysis of a homogeneous patient group with standardised operative procedure.

BChE activity could be regarded as an inflammatory parameter in this context. In the literature, lower levels of BChE activity have already been described during inflammatory processes, stress and malnutrition. ${ }^{9} 1122$ Therefore, lower levels of BChE activity in complication group might reflect perioperative inflammation, which is known to promote complications like delirium or infections. ${ }^{20} 23$ Conventional markers like CRP and leucocytes did not differ in both groups.

Delirium is a complex symptom that is very common in operative and nonoperative disciplines in the course of hospital stay. The incidence is especially high among patients undergoing heart surgery. ${ }^{24}$ The incidence in this patients' population has been described to be from 30 up to $80 \% .{ }^{25}$ The incidence of delirium after TAVI is reported as $29 \%$ in the literature. ${ }^{6}$ Delirium occurred significantly more frequently following TA procedures. ${ }^{26}$ In the present study, $26.7 \%$ of the patients were diagnosed with delirium overall. There was no difference depending on TA or TF approach. Perioperative measurement of AChE and BChE did not discern between patients with and without delirium, which is in accordance with the findings by John et $a l^{17}$.

The present study highlights the validity of BChE measurements for early detection of high-risk patients after TAVI. Surprisingly, the BChE assessment proved more effective than the EuroSCORE in discriminating between the patient groups making it a valuable biomarker for the early detection of high-risk patients. EuroSCORE is a well-established clinical assay for the patient mortality analysis ${ }^{27}$ and requires documenting multiple and diverse data sets. The data sets are in most cases readily available; however, in some cases, a particular set of data might not be accessible, delaying or making the scoring impossible. By using a POCT system for a single BChE measurement, the results of an equally efficient outcome assessment tool are readily available at the bedside and may complete conventional assessments. Further studies with a greater patient population are needed to investigate the clinical implications.

Prompt assessment of the systemic immune response with an immediate, rapid and affordable bedside measurement of the BChE activity might improve risk evaluation and help optimise postoperative management and therapy of patients after TAVI. Predicting the length of the hospital stay might play an important role in staff and resource management for these patients.

\section{Limitations}

Limitations of the present study might be the short duration of 3 days' measurement. Blood was taken from each patient; in case the analysis could not be performed immediately (during anaesthesia induction), the sample was cooled down in a refrigerator. Maybe values of AChE and BChE changed in combination with lower temperature. Furthermore, it was only one measurement performed with each sample, so no control values could be achieved.

The study protocol required daily cholinesterase activity measurements in the postoperative period, without specifying time or requesting multiple daily measurements. Therefore, circadian fluctuations in enzyme activities could not be considered.

The biggest limitation of the present study is the low number of included patients and the related statistical power. Further studies with larger patient groups and with focus on the underlying mechanisms of the different complications would be needed to validate our findings and the clinical implications. A larger, possibly multicentre study would be needed to evaluate more postoperative complications and the roles of $\mathrm{BChE}$ and $\mathrm{AChE}$ in particular complications.

\section{Author affiliations}

${ }^{1}$ Department of Gastroenterology, University Hospital Regensburg, Regensburg, Germany

${ }^{2}$ Department of Cardiothoracic Surgery, University Hospital Regensburg, Regensburg, Germany 
${ }^{3}$ Department of Anesthesiology, University Hospital Regensburg, Regensburg, Germany

${ }^{4}$ Department of Neurology - Center of Vascular Neurology and Intensive Care Medicine, University of Regensburg, Regensburg, Germany

${ }^{5}$ Department of Anesthesiology and Intensive Care Medicine, Campus Charité Mitte and Campus Virchow-Klinikum, Charité Universitätsmedizin Berlin, Berlin, Germany ${ }^{6}$ Department of Anesthesiology and Intensive Care Medicine, Klinikum Aschaffenburg-Alzenau, Aschaffenburg, Germany

Contributors DIB, YAZ, AM, AH and BM were responsible for study design, statistical analyses and drafting of the manuscript. WP, $A B, B M$ and $B M G$ performed the experiments and drafted the manuscript. BM and AM were responsible for statistical analysis. All authors read and approved the final manuscript.

Funding The authors have not declared a specific grant for this research from any funding agency in the public, commercial or not-for-profit sectors.

Competing interests None declared.

Patient and public involvement Patients and/or the public were not involved in the design, or conduct, or reporting, or dissemination plans of this research.

Patient consent for publication Not required.

Ethics approval This work is approved by the local independent Charite Ethics Committee, Charité-Universitätsmedizin Berlin, Germany (ref.: EA1/220/13) on 14 August 2013. After further approval of the local ethics board of the University of Regensburg, a total of 48 patients were included in the study between March 2014 and June 2016 at University Hospital of Regensburg. Written informed consent was obtained from each patient.

Provenance and peer review Not commissioned; externally peer reviewed. Data availability statement № data are available.

Open access This is an open access article distributed in accordance with the Creative Commons Attribution Non Commercial (CC BY-NC 4.0) license, which permits others to distribute, remix, adapt, build upon this work non-commercially, and license their derivative works on different terms, provided the original work is properly cited, appropriate credit is given, any changes made indicated, and the use is non-commercial. See: http://creativecommons.org/licenses/by-nc/4.0/.

\section{ORCID iDs}

Andre Bredthauer http://orcid.org/0000-0002-5779-7714

Diane Inge Bitzinger http://orcid.org/0000-0002-3080-9957

\section{REFERENCES}

1 Rodés-Cabau J, Webb JG, Cheung A, et al. Transcatheter aortic valve implantation for the treatment of severe symptomatic aortic stenosis in patients at very high or prohibitive surgical risk: acute and late outcomes of the multicenter Canadian experience. J Am Coll Cardiol 2010;55:1080-90.

2 Zahn R, Gerckens U, Grube E, et al. Transcatheter aortic valve implantation: first results from a multi-centre real-world registry. Eur Heart J 2011;32:198-204.

3 Leon MB, Smith CR, Mack M, et al. Transcatheter aortic-valve implantation for aortic stenosis in patients who cannot undergo surgery. N Engl J Med 2010;363:1597-607.

4 Würschinger F, Wittmann S, Goldfuß S, et al. Complications after transcatheter aortic valve implantation using Transfemoral and transapical approach in general anaesthesia. PLoS One 2018;13:e0193558.

5 Covello RD, Ruggeri L, Landoni G, et al. Transcatheter implantation of an aortic valve: anesthesiological management. Minerva Anestesiol 2010;76:100-8.
6 Maniar HS, Lindman BR, Escallier K, et al. Delirium after surgical and transcatheter aortic valve replacement is associated with increased mortality. J Thorac Cardiovasc Surg 2016;151:815-23.

7 Chiarla C, Giovannini I, Giuliante F, et al. Plasma cholinesterase correlations in acute surgical and critical illness. Minerva Chir 2011;66:323-7.

8 Al-Kassab AS, Vijayakumar E. Profile of serum cholinesterase in systemic sepsis syndrome (septic shock) in intensive care unit patients. Clin Chem Lab Med 1995;33:245.

9 Das UN. Acetylcholinesterase and butyrylcholinesterase as possible markers of low-grade systemic inflammation. Med Sci Monit 2007;13:RA214-21.

10 Distelmaier K, Winter M-P, Rützler K, et al. Serum butyrylcholinesterase predicts survival after extracorporeal membrane oxygenation after cardiovascular surgery. Crit Care 2014;18:R24.

11 Lampón N, Hermida-Cadahia EF, Riveiro A, et al. Association between butyrylcholinesterase activity and low-grade systemic inflammation. Ann Hepatol 2012;11:356-63.

12 Zivkovic AR, Bender J, Brenner T, et al. Reduced butyrylcholinesterase activity is an early indicator of traumainduced acute systemic inflammatory response. J Inflamm Res 2016;9:221-30.

13 Zivkovic AR, Schmidt K, Sigl A, et al. Reduced serum butyrylcholinesterase activity indicates severe systemic inflammation in critically ill patients. Mediators Inflamm 2015;2015:1-11.

14 Kamolz L-P, Andel H, Greher M, et al. Serum cholinesterase activity in patients with burns. Clin Chem Lab Med 2002;40:60-4.

15 Zivkovic AR, Decker SO, Zirnstein AC, et al. A sustained reduction in serum cholinesterase enzyme activity predicts patient outcome following sepsis. Mediators Inflamm 2018;2018:1-10.

16 Cerejeira J, Batista P, Nogueira V, et al. Low preoperative plasma cholinesterase activity as a risk marker of postoperative delirium in elderly patients. Age Ageing 2011;40:621-6.

17 John M, Ely EW, Halfkann D, et al. Acetylcholinesterase and butyrylcholinesterase in cardiosurgical patients with postoperative delirium. J Intensive Care 2017;5:29.

18 Carnahan RM, Lund BC, Perry PJ, et al. The anticholinergic drug scale as a measure of drug-related anticholinergic burden: associations with serum anticholinergic activity. J Clin Pharmacol 2006;46:1481-6.

19 Radtke FM, Franck M, Schneider M, et al. Comparison of three scores to screen for delirium in the recovery room. $\mathrm{Br} J$ Anaesth 2008;101:338-43.

20 Cerejeira J, Nogueira V, Luís P, et al. The cholinergic system and inflammation: common pathways in delirium pathophysiology. J Am Geriatr Soc 2012;60:669-75.

21 Zivkovic AR, Schmidt K, Stein T, et al. Bedside-measurement of serum cholinesterase activity predicts patient morbidity and length of the intensive care unit stay following major traumatic injury. Sci Rep 2019;9:10437.

22 Santarpia L, Grandone I, Contaldo F, et al. Butyrylcholinesterase as a prognostic marker: a review of the literature. J Cachexia Sarcopenia Muscle 2013;4:31-9.

23 De Magistris L, Paquette B, Orry D, et al. Preoperative inflammation increases the risk of infection after elective colorectal surgery: results from a prospective cohort. Int J Colorectal Dis 2016;31:1611-7.

24 Klugkist M, Sedemund-Adib B, Schmidtke C, et al. Confusion assessment method for the intensive care unit (CAM-ICU): Diagnostik des postoperativen delirs bei kardiochirurgischen Patienten. Anaesthesist 2008;57:464-74.

25 Koster S, Oosterveld FGJ, Hensens AG, et al. Delirium after cardiac surgery and predictive validity of a risk checklist. Ann Thorac Surg 2008;86:1883-7.

26 Tilley E, Psaltis PJ, Loetscher T, et al. Meta-Analysis of prevalence and risk factors for delirium after transcatheter aortic valve implantation. Am J Cardiol 2018;122:1917-23.

27 Nashef SA, Roques F, Michel P, et al. European system for cardiac operative risk evaluation (EuroSCORE). Eur J Cardiothorac Surg 1999;16:9-13. 